\title{
Una aproximación a la gestión pública comunitaria europea desde una perspectiva intergubernamental
}

\section{Jorge Crespo González *}

\section{Introducción}

El proceso de integración europeo en torno a las Comunidades Europeas (CCEE) puede explicarse como un serio intento de superación de los Estados nacionales, demasiado presos del concepto de soberanía nacional, por una organización compleja que integra lógicas intergubernamentales y supranacionales, que alienta la actuación de múltiples actores a diferentes niveles y con diferentes estatutos, y que privilegia la noción de soberanía compartida. En este entorno, es relevante conocer cómo se establecen las relaciones entre los Estados miembros (EEMM) con las CCEE, y con qué herramientas y técnicas de gestión cuentan. No es esta última una cuestión menor y simple de afrontar, toda vez que el escenario comunitario recuerda a la caracterización de KINGDOM: un entorno en que los participantes presentan preferencias problemáticas, con un instrumental tecnológico incierto, y en un proceso de participación fluida.

Un dato que condiciona un análisis desde la gestión pública es la especialización funcional de las CCEE en tres categorías de intervenciones: regulación de carácter estratégico, ya sea en términos intergubernamentales o supranacionales; control de la aplicación de los actos comunitarios; y financiación de algunos programas, esencialmente a través de los fondos. De esta manera, la fase de aplicación de las políticas, que es aquella en que esencialmente toman cuerpo los valores de gestión vinculados a la dimensión operativa, sólo se efectúa excepcionalmente de modo directo por los órganos comunitarios, siendo lo habitual la instrumentalización a través de las Administraciones nacionales. De ahí que cuando hablemos de gestión pública en la Unión Europea (UE), no debamos identificar el concepto de «gestión» con el manejo de determinados conocimientos y técnicas vinculados a la prestación directa de bienes y servicios, sino, mucho más abstractamente, a la capacidad de intervenir en la realidad a través de regulaciones, financiaciones, controles, y terceros actores (sean éstos gubernamentales e institucionales, o no). Esta concepción nos acerca a la metodología de análisis que aporta la gestión intergubernamental, pues nos permite afrontar las interacciones entre los actores que intervienen en las políticas públicas multinivel, esencialmente en la fase de aplicación, otorgando una marcada prioridad por las actividades orientadas a la resolución de problemas mediante la acción conjunta y la gestión indirecta.

Este trabajo tiene por objeto analizar algunas de las dimensiones más importantes de la gestión intergubernamental en la Unión Europea, a partir de las relaciones e interacciones que se producen entre la Administración comunitaria europea y las propias de los diferentes EEMM. Las dimensiones tratadas son: la regulación (I), las subvenciones intergubernamentales (II), las relaciones centro/periferia y la convergencia político-administrativa (III). 


\section{La regulación}

\section{I.1. Importancia, diversidad y complejidad}

El sistema comunitario de regulación es un elemento del máximo interés para la gestión intergubernamental por su importancia intrínseca, diversidad y complejidad.

La importancia le viene dada por el hecho de crear y modificar las relaciones entre las instituciones político-administrativas y sus respectivas sociedades; por la circunstancia de hacer nacer y alterar el equilibrio entre las instituciones comunitarias y EEMM; y, por último, por la constatación de que el estilo de formulación del Derecho comunitario altera la naturaleza de la política de que se trate ${ }^{2}$.

La diversidad se asocia no solamente a la dificultad material de regular en más de veinte áreas distintas, sino también a la existencia de diferentes instrumentos de regulación, entre los que cabe citar, sin querer ser exhaustivos, los tradicionalmente conocidos (tratados, reglamentos, directivas, decisiones y recomendaciones), pero también otros complementarios (por ejemplo, los planes de acción) e incluso la incorporación paulatina de determinados principios que forman la actividad normativa comunitaria (piénsese en el de «desarrollo sostenible», y en la importancia de la jurisprudencia comunitaria).

Desde luego, el retrato no quedaría completo si no aludimos a la complejidad de gestión que agrega la existencia de diferentes políticas comunitarias especializadas, con diferentes grados de europeización, y que utilizan diferentes herramientas de normación.

\section{I.2. Políticas comunitarias y regulación}

Siguiendo a Goma y SubrRats ${ }^{3}$ (1998: 392 y ss.), podemos hacer diferencias entre las políticas públicas comunitarias de acuerdo con el tipo de europeización realizado (si la intensidad de dicha europeización ha sido alta, media o baja, y si la misma se ha intervenido de forma extensiva, sobre la política en su conjunto, o de manera selectiva, sobre algún aspecto concreto) y los instrumentos utilizados en su europeización.

De esta manera nos encontramos con tres tipos de segmentos de politicas:

a) Altamente europeizado, ya sea de manera extensiva (política industrial, energética, medioambiental y de telecomunicaciones) y cuya integración se ha realizado a través de directivas; o de manera selectiva (política fiscal y de inmigración), cuya integración se ha intervenido mediante disposiciones normativas del Tratado. b) Medianamente europeizado, donde de acuerdo con la incidencia normativa comunitaria sobre las correspondientes políticas pueden distinguirse las que han sido objeto de programas de acción europeos con escasa o nula dimensión legislativa (políticas activas de empleo y políticas de igualdad de género), de aquellas para las que existen regulaciones europeas de carácter no vinculante (políticas de protección social), o, finalmente, de aquellas cuya europeización ha provocado importantes respuestas de adaptación en el ámbito estatal (política sanitaria y de mercado de trabajo).

c) Escasamente europeizado, que integraría políticas que prácticamente no han sufrido el efecto de la elaboración normativa comunitaria (política educativa, de vivienda y lingüística), y cuyos núcleos de decisión y aplicación se encuentran vinculados a los poderes nacionales $y / o$ subnacionales.

\section{I.3. Integración negativa y positiva}

Otra forma de ver la complejidad de la regulación comunitaria, abstrayéndose del laberinto material de las políticas individualmente consideradas, se realiza a través de la alianza de la actuación normativa de la Unión con determinados aspectos relacionados fundamentalmente con la creación, o corrección, de los mercados, y de sus posibles implicaciones para una adaptación adecuada tanto a un entorno globalizado como a una perspectiva de gestión multinivel, no exenta de consideraciones de legitimidad democrática. Esa manera de ver se concreta mediante los conceptos de integración positiva y negativa. Su definición previa nos permitirá posteriormente obtener algunas consecuencias desde una perspectiva de gestión.

De acuerdo con SCHARPF (2000: 59), «la integración negativa se refiere a la eliminación de los aranceles, restricciones cuantitativas y otras barreras al comercio u obstáculos a la competencia libre y no distorsionada», mientras que la integración positiva alude a «la reconstrucción de un sistema de regulación económica en el nivel de la unidad económica más amplia». Con todo, y a riesgo de ser un tanto simplificadores, podemos considerar la primera como las intervenciones políticas y económicas tendentes a la creación de mercados, en tanto que la segunda podríamos identificarla con las intervenciones políticas y económicas orientadas fundamentalmente, aunque no exclusivamente, a la corrección de los mismos.

\section{I.4. Regulación y rendimiento}

Es difícil saber en qué medida la gestión de un modelo de regulación aporta rendimiento a un sistema político-administrativo. Para ello haría falta la elaboración de estudios empíricos en que fueran muy bien definidos los indicadores de rendimiento susceptibles de medir los resultados causalmente deri- 
vados de la elección de un modelo regulativo u otro, con independencia de otras posibles concausas. No obstante, sí puede realizarse una primera aproximación a partir de algunos de los criterios que ha aportado la OCDE (1997), adaptándolos al ámbito comunitario. Un examen detenido nos permitirá cuestionar algunos de los lugares comunes.

En primer lugar, es lógico pensar que ha de obtenerse una mejora del rendimiento si se mejora la comunicación, la coordinación y, por tanto, trasladado a nuestro ámbito, si se vincula a los diferentes niveles de gobierno en el proceso de adopción de decisiones y de ejecución del Derecho comunitario. Como algún autor ha hecho notar ${ }^{4}$, los procesos de negociación y concertación de intereses entre niveles de gobiernos y actores privados que se producen en el escenario comunitario, propician que las decisiones adoptadas sean superiores a las que los EEMM serían capaces de tomar aisladamente, en la medida en que se acercan al óptimo paretiano, pues han superado obstáculos importantes hasta llegar a constituir acuerdos negociados. Pero, por otra parte, también es posible defender que el modelo comunitario de adopción y ejecución de decisiones políticas, al privilegiar la decisión conjunta así como la obtención del consenso penalizando seriamente las opciones radicales, conduce a un modelo presidido por la negociación a la baja y, probablemente, por la adopción de decisiones subóptimas ${ }^{5}$.

Más clara, sin embargo, es la existencia de una responsabilidad compartida, en lo referido a la fase de creación del Derecho comunitario y de aplicación del mismo, entre la Administración comunitaria y las AANN (aunque conviene no olvidar el papel de las constelaciones de actores no gubernamentales). Si nos centramos en la fase de aplicación, es interesante resaltar que los actos comunitarios más importantes que favorecen dicha responsabilidad compartida son las directivas, toda vez que, como es sabido, exigen una acción previa (la transposición) por parte de los EEMM ${ }^{6}$.

Acaso la gestión más determinante, por sus resultados, desde el punto de vista regulativo ha sido aquella afianzada en la integración negativa. Ésta ha sido utilizada para liberalizar y privatizar sectores enteros de los EEMM que de otra manera habrían provocado fuertes conflictos políticos internos. En efecto, con muchas probabilidades, ningún Estado miembro hubiera podido lanzar el ataque legal al estatuto privilegiado del servicio público y de algunos monopolios amparándose en la legislación nacional sobre competencia. Esto se logró a partir de la constitucionalización del Derecho de la competencia a nivel europeo, con lo que la Comisión pudo utilizar sus directivas (que no exigen el acuerdo del Consejo), junto a la interpretación favorable del Tribunal de Justicia de las CCEE (TJCE), para iniciar procesos contra las infracciones nacionales. De esta manera ha logrado la liberalización sucesiva de distintas áreas del servicio público (transporte aéreo, aeropuertos, correos, servicios telefónicos, etc.). Este comportamiento de la Comisión y del TJCE comporta una ventaja para los gobiernos en ejercicio de los EEMM, pues les permite adoptar decisiones evitando fuertes controversias políticas con sus respectivas oposiciones internas ${ }^{7}$. No obstante, y para ser justos, también debe consignarse que en la actualidad estamos asistiendo a una cierta limitación de la capacidad liberalizadora y privatizadora de la integración negativa y del Derecho comunitario de la competencia, al incluirse en los acuerdos de Amsterdam determinadas declaraciones y protocolos que permiten la protección de diversas áreas de servicios públicos, como, por ejemplo, los bancos públicos alemanes o los servicios públicos de radiotelevisión.

Por otra parte, la gestión derivada de la integración positiva es más limitada. Su capacidad de resolver problemas depende de la política concreta de que se trate, de los comportamientos $\mathrm{e}$ intereses de las diferentes constelaciones de actores, y del procedimiento de adopción del acuerdo. Así, si el interés comunitario es convergente o complementario de los intereses nacionales, la Comisión podría avanzar más audazmente en la integración de la política afectada (piénsese, por ejemplo, en la regulación de la calidad de los productos); pero si, por el contrario, existe posibilidad de veto y los intereses son divergentes, se frenaría la adopción de acuerdos y la posible integración de la política de que se trate (así ocurre con las normas orientadas a la corrección del mercado).

\section{I.5. Regulación y control}

El control de la aplicación de los actos comunitarios se realiza esencialmente a posteriori, y en él se implican, a diferente título, las AANN, la Comisión (en tanto institución no jurisdiccional encargada de velar por el cumplimiento del Derecho comunitario) y el TJCE. A pesar de que la forma de control pueda implicar, antes de llegar a una fase jurisdiccional, relaciones de comunicación, intercambio y cooperación entre la Comisión y los intereses, gubernamentales o no, afectados, no puede decirse que no se produzcan las deficiencias que se observan en los procesos de control a posteriori fuertemente judicializados, a saber, una predilección por la observancia detallada de regulaciones y procedimientos, y no tanto por el contraste a partir de objetivos de gestión y resultados.

Para el control sobre el terreno, en el ámbito de los EEMM, se están fomentando diversas prácticas, tal como describe SPA. NOU (1999: 46) para el caso griego:

a) La creación de comités de seguimiento responsables de seguir la implantación del Derecho comunitario fuera de los órganos ministeriales.

b) La designación de consultores privados, bajo la presión de la UE, para el control de los programas operativos regionales. 


\section{Las subvenciones intergubernamentales}

Entendemos por subvenciones intergubernamentales el conjunto de transferencias de recursos financieros que tienen lugar entre organizaciones pertenecientes a distintos niveles territoriales de gobierno. En el caso que nos ocupa es claro que la organización que financia es la UE, en tanto que las organizaciones receptoras son las AANN (incluyendo las subnacionales).

\section{II.1. Importancia cuantitativa}

La importancia cuantitativa de los pagos comunitarios a los EEMM es incuestionable, especialmente para aquellos países receptores de importantes sumas a cargo de los fondos estructurales y de cohesión ${ }^{8}$ (véase, para el caso español, el cuadro que presenta el saldo financiero de España con las CCEE). Pero tampoco debe menospreciarse su relevancia cualitativa, de acuerdo con los aspectos que desarrollamos a continuación.

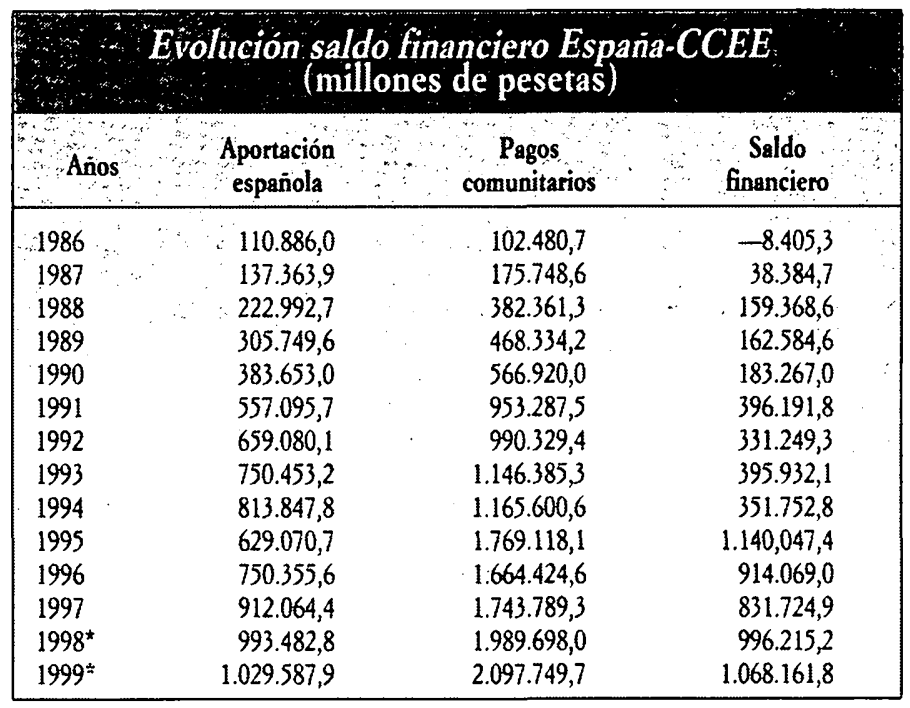

Fuente: Dirección General del Tesoro.

* Previsiones de caja.

\section{II.2. Importancia cualitativa}

\section{Cabe tener en cuenta cuatro consideraciones:}

En primer lugar, es preciso recordar que en los últimos años estamos asistiendo a un incremento de la financiación intergubernamental de los diferentes niveles de gobierno, especialmente los subnacionales, lo que implica la posibilidad de aumentar los contactos entre Administraciones para encontrar objetivos, posibilidades de actuación y de gestión conjunta, así como controles que justifiquen la puesta en común de los recursos económicos. En el caso comunitario, esta circunstancia ha posibilitado no sólo un trasvase de recursos más o menos importante, sino también una modificación de la propia naturaleza de la acción pública, ya que las Administraciones financiadas se han visto obligadas a reforzar sus potencialidades de planificación y control, y a integrar comportamientos tendentes a la gestión cooperativa. Esto es coherente con el hecho de que la Comisión tenga la responsabilidad general de la ejecución del presupuesto comunitario, mientras las AANN se encarguen de dos tareas básicas: participar en la ejecución de las decisiones del Consejo a través del correspondiente comité consultivo, de gestión (por ejemplo, en el ámbito agrícola), o regulador (por ejemplo, en el área de subvenciones a la microbiología); y ejecutar detalladamente y cotidianamente las decisiones financieras, tanto desde el punto de vista de los ingresos como de los gastos (así, en el ámbito agrícola gestionan las subvenciones comunitarias a las explotaciones agrarias a través de organismos especializados, ofreciendo incluso anticipos a cuenta). De esta forma, tal como explican CASSESE y Della Cananea (1990: 74), citando a STRASSER, «la gestión de los gastos se caracteriza por un sistema comunitario de financiación centralizado y un sistema de pagos descentralizado».

En segundo lugar, la financiación intergubernamental comunitaria privilegia la utilización de subvenciones condicionadas frente a las genéricas, y es sabido que las transferencias de carácter condicionado son un instrumento básico para la coordinación de las políticas públicas que implican a distintos niveles de gobierno. Con este tipo de subvención, al vincularse a áreas específicas de actuación o a programas concretos, se garantizan mejor los objetivos y racionalidades comunitarios (asegurar el interés comunitario, controlar la actuación de los receptores, y mantener relaciones estables con los destinatarios) sin menoscabar los propios de las organizaciones receptoras (vincular los intereses subnacionales o nacionales al comunitario, obtener un flujo de recursos lo más abundante posible, modernizar sus organizaciones, respeto del principio de subsidiariedad, etc.).

En tercer lugar, las transferencias intergubernamentales pueden utilizarse para incrementar la capacidad europea para la resolución de problemas, en la medida en que, ante la posibilidad de un conflicto de intereses o ideologías entre gobiernos nacionales en el Consejo, son susceptibles de obtener alteraciones en las posiciones negociadoras de los más reticentes a cambio de compensaciones financieras.

$\mathrm{Y}$, en cuarto lugar, y en coherencia con todo lo anterior, conviene recordar algunos de los criterios que deben observarse en la gestión de las subvenciones comunitarias y que afectan a la modificación del comportamiento interno de las AANN ${ }^{9}$. Así, pueden mencionarse los siguientes: necesariedad, adiciona- 
lidad, grado de financiación requerida, la coordinación y comunicación intergubernamental e interinstitucional, control, etc.

\section{II.3. La gestión y el control de las subvenciones}

Por otra parte, y cambiando la perspectiva, es pertinente hacer una breve referencia a la gestión de los fondos y a su control.

A efectos de gestión, y en aplicación del principio de subsidiariedad, la ejecución de las intervenciones corresponde a los EEMM, sin perjuicio de las competencias de la Comisión (sobre todo por sus funciones en materia de ejecución del presupuesto general de las CCEE). Los EEMM podrán designar «autoridades de gestión» que podrían adquirir carácter público o privado, y/o, adoptar una perspectiva territorial (nacional, regional o local). Esas «autoridades de gestión» serían responsables de la eficacia y regularidad de la gestión y ejecución de los fondos, sobre todo en lo referido a la recogida de datos financieros, indicadores y estadísticas ${ }^{10}$. De esta forma, cada año deberá presentarse un informe de gestión ante la Comisión.

Por su parte, la responsabilidad de control, en primera instancia, corresponde al Estado receptor, sin perjuicio de los controles que pudiera establecer la Comisión, aleatoriamente o siguiendo algún indicio de irregularidad, durante el desarrollo del proyecto, o una vez entregado el informe anual ${ }^{11}$. El Estado afectado creará un Comité de Seguimiento para supervisar las acciones nacionales dentro de cada Marco Comunitario de Apoyo o de cada Documento Único de Programación. Dicho Comité, que estará encargado igualmente de aprobar el informe anual antes de ser remitido a la Comisión, se constituirá de acuerdo con la «autoridad de gestión», y, cuando proceda, integrará a representantes del Banco Europeo de Inversiones o de la Comisión Europea. Así se garantiza una composición intergubernamental plural susceptible, en principio, de realizar controles y evaluaciones de acuerdo a consideraciones técnicas y político-administrativas.

III. Relaciones centro/periferia y convergencia político-administrativa

Para poder realizar una cabal composición de cómo se establecen las relaciones entre la UE y los EEMM es necesario previamente detenerse, aunque sea con mucha brevedad, en el análisis del papel histórico que le corresponde en nuestros días al Estado.

\section{III.1. La crisis del Estado en el escenario comunitario}

En la actualidad es un lugar común la constatación de que el Estado, en tanto construcción histórica, se encuentra en una etapa de transformación y crisis. En efecto, dos procesos simultáneos cuestionan su papel histórico y su carácter de depositario de la soberanía nacional: la aparición de fenómenos nuevos cuya resolución supera las posibilidades de actuación del Estado nación tradicional, dando ocasión a intervenciones desde el ámbito internacional o supranacional; y la irrupción en muchos Estados de manifestaciones federales, regionales y locales, que permiten dar una respuesta más cercana y eficaz a determinados problemas. Ambos procesos no sólo se revelan como respuestas más interesantes a determinadas cuestiones en el plano de los rendimientos, sino que incluso, desde una posición identitaria e institucional, compiten en el plano simbólico para legitimarse de cara a sus correspondientes ciudadanías.

Como no podía ser de otra forma, la puesta en escena de más niveles públicos de actuación ha ido dotando de mayor complejidad al reparto de responsabilidades, sobre todo en los sectores de la educación, sanidad y de la protección social. Es constatable que se han incrementado vigorosamente las funciones compartidas, y las relaciones de interdependencia entre niveles de gobierno y que, por otra parte, los comportamientos de unos y de otros oscilan entre la colaboración, la confrontación, la negociación y el paternalismo.

Un ejemplo que ilustra el nuevo escenario de doble erosión del Estado nacional es la política de medioambiente. Tal como escriben BULLER y HOGGART (1998: 156), «... la internacionalización de la política de medio ambiente altera significativamente el rol de los gobiernos nacionales y de las instituciones encargadas del medio ambiente a nivel local, sobre todo en lo que se refiere a la definición de agendas ambientales, a la determinación y evaluación de la degradación y calidad del medio ambiente, y a la selección de los instrumentos para una gestión ambiental efectiva, así como a la representación de las demandas de los ciudadanos».

Todo esto, desde la perspectiva de la gestión pública, nos lleva a plantear dos problemas: por una parte, cuál es la escala política más apropiada para gestionar determinadas políticas, es decir, la cuestión de la subsidiariedad, y, por otra, cuál es la escala geográfica más apropiada para hacerlo, es decir, la cuestión de la territorialidad.

En el entorno comunitario europeo, se ha intentado dar respuesta desde la doctrina al reto teórico que representa la nueva 
situación. Acaso el enfoque empírico más importante, desde la perspectiva de integrar con más claridad la problemática de los diversos niveles de gobierno, sea el de Multilevel Governance. La gobernanza multinivel ${ }^{12}$ concibe la integración europea como la edificación de una nueva entidad política en la que la responsabilidad sobre las diversas intervenciones que incluyen las políticas públicas se encuentra compartida entre múltiples niveles de gobierno (supranacional, nacionales y subnacionales). El nivel de gobierno nacional sigue siendo el esencial, pero ya no afianzado en el concepto de una soberanía nacional cada vez más débil y erosionada, sino en el de soberanía compartida con buenas dosis de legitimidad de resultado. Esta gobernanza multinivel comunitaria permite movilizar a actores gubernamentales y no gubernamentales en la formulación e implantación de las políticas comunitarias (aunque con matices diferentes, de acuerdo con cada política), es más adecuada para aquellas áreas en que la acción pública coordinada es más eficaz y eficiente, y aboga por comportamientos que favorecen la negociación.

Finalmente, es interesante citar la existencia de varios principios articuladores de las relaciones entre la UE y los EEMM, entre los que destacan los de colaboración/cooperación, autonomía institucional, y subsidiariedad. Especial relevancia tiene, a efectos de nuestro análisis, el de autonomía institucional. Se trata de un principio de construcción jurisprudencial que ha sido reiterado numerosas veces por el Tribunal de Justicia de las Comunidades Europeas. Este principio implica que las medidas necesarias para la aplicación del Derecho comunitario en los ordenamientos nacionales deben ser tomadas y asumidas, en el marco de los EEMM, por aquellas instituciones nacionales que corresponda de acuerdo con sus propios procedimientos y distribución interna del poder. Es lógico que así sea ya que las Comunidades no se han provisto de «un ejército de funcionarios dispuestos a actuar en los más remotos rincones de cada uno de los Estados miembros...», por lo que cada uno de ellos lo aplicará apoyándose en sus propios agentes y utilizando la organización interna constitucionalmente prevista ${ }^{13}$. Lo que significa, pura y simplemente, que las Comunidades Europeas no están interesadas en cuál sea la organización administrativa interna de cada uno de los Estados, ni en si existe un régimen de distribución territorial del poder político-administrativo ${ }^{14}$, sino en que sus disposiciones sean efectivamente cumplidas ${ }^{15}$.

\section{III.2. Las relaciones centro/periferia}

Entendemos por relaciones centro/periferia aquellas que se producen entre la Administración comunitaria y las AANN de los EEMM. Según explicaremos a continuación, las relaciones distan de poder establecerse en términos monolíticos, ya que ni en las actividades presuntamente centralizadas la Adminis- tración comunitaria puede actuar sin el concurso del resto, ni en las relaciones pretendidamente descentralizadas las AANN disponen de total discrecionalidad.

\section{III.2.1. Una centralización decisoria muy participada}

La Administración comunitaria (fundamentalmente la de la Comisión Europea) tiene un papel muy destacado en el proceso de toma de decisiones y de elaboración de actos comunitarios, pues tiene funciones imprescindibles que le han sido reconocidas por los Tratados. Entre ellas cabe citar las competencias de iniciativa legislativa, de control del Derecho comunitario, de negociación de tratados internacionales, de administración del presupuesto comunitario y de los fondos, etc. Una de ellas, y no la menor, es la de iniciativa legislativa, que conjuga más o menos armónicamente las actuaciones de la Comisión y del resto de instituciones, con complejas interacciones con las AANN y otros actores. A ello nos referimos a continuación para mostrar hasta qué punto las AANN son esenciales en el funcionamiento de la UE.

En efecto, la intervención de las AANN es determinante y exclusiva en algunas de las fases del procedimiento decisorio (por ejemplo, en los grupos de trabajo del Consejo de la Unión, así como en el Coreper). Su intervención se produce no sólo en la fase de aplicación de los actos comunitarios en el ordenamiento interno (fase descendente), sino también en la etapa de creación de dichos actos (fase ascendente).

Desde el punto de vista de la fase ascendente, la participación de las AANN se torna primordial, pues la Unión no siempre dispone de recursos para obtener información sólida sobre los sectores o actores afectados por la regulación que proyecta y, aunque es cierto que puede apoyarse en los datos que le dan los propios actores, o los correspondientes grupos de presión e interés, no lo es menos que dichas informaciones pueden adolecer de un cierto subjetivismo y unilateralidad. De ahí que las AANN proporcionen a las instituciones comunitarias informaciones que les permitan verificar y contrastar la obtenida a través de otros medios ${ }^{16}$. Y, recíprocamente, para las AANN es el momento de dar a conocer, en la medida de lo posible, cuál es la situación en sus Estados de los diferentes sectores afectados, y cuáles son los aspectos más sensibles de la misma, de forma que pueda tenerse en cuenta en el proceso decisorio comunitario.

Es indudable que el conocimiento de cuál es la situación real en cada Estado del ámbito material afectado por la regulación comunitaria favorece dicho proceso, pues introduce elementos que si son tenidos en cuenta no sólo estarán sobre la mesa en las sucesivas negociaciones, sino que a la postre facilitarán la implantación del acto jurídico comunitario en los ordenamientos jurídicos nacionales afectados, es decir, en la 
fase descendente. No es ésta una cuestión menor, pues en el escenario comunitario el requerimiento de que la legislación comunitaria se vea desprovista, en la medida de lo posible, de obstáculos de ejecución se hace más evidente si consideramos que ésta se efectúa excepcionalmente de modo directo por los órganos comunitarios, siendo lo habitual la implantación a través de los órganos correspondientes de las AANN.

A nuestro modo de ver, ninguna de las competencias que ejerce la Administración comunitaria responde al patrón de una estricta centralización, al menos en su sentido funcional, pues incluso aquellas como, por ejemplo, las referidas a la administración del presupuesto, exigen, desde el punto de vista de la recaudación, la actividad decisiva de los EEMM. Por otra parte, debe tenerse en cuenta también el freno que supone para una centralización más allá de lo razonable la asunción, desde el Tratado de la Unión Europea (TUE), del principio de subsidiariedad como criterio para el reparto de funciones entre la UE y los EEMM.

\section{III.2.2. Una descentralización ejecutiva vigilada}

En otro lugar fue puesto de manifiesto cómo la Administración comunitaria, para implantar sus actos en los EEMM, en ausencia de desconcentración periférica ${ }^{17}$ cuenta con una casi total descentralización ejecutiva ${ }^{18}$.

De acuerdo con el principio de autonomía institucional, es preciso recordar que, a estos efectos, para la Administración comunitaria es indiferente cuál sea la organización administrativa doméstica de los EEMM, y si éstos mantienen o no un sistema de distribución territorial del poder, siempre que se apliquen convenientemente los actos comunitarios. Sin duda, la mayor discrecionalidad de las AANN se produce en la aplicación de las directivas, pues exige también su previa ejecución normativa.

En todo caso, esa descentralización ejecutiva de los actos comunitarios cuenta con importantes factores que hasta cierto punto «comunitarizan» la labor de implantación desde el punto de vista de los valores y de las actividades administrativas nacionales: por una parte, las labores de control que realiza la Administración comunitaria, que exige órganos de seguimiento y registro de datos, etc.; por otra, el hecho significativo de que algunos de los actos son financiados con cargo al presupuesto comunitario, lo que supone, en principio, que pueden utilizarse las transferencias europeas como elemento coactivo para exigir un mayor compromiso con los objetivos de los actos comunitarios, y, finalmente, la importante labor del TJCE ${ }^{19}$, tanto en su vertiente interpretativa del alcance real de las obligaciones de los EEMM afectados por el Derecho comunitario, como en los correspondientes recursos de incumplimiento.

\section{III.3. La cuestión de la convergencia de las AANN}

La convergencia de las AANN en el escenario comunitario, más allá del debate más o menos politizado que pueda despertar, es una necesidad. A él empujan algunos factores que vamos a destacar a continuación, aunque igualmente otros actúan como rémoras. También resulta de interés intentar vislumbrar en qué consisten algunas de las mejoras que podrían realizarse, otorgando la importancia debida a la dimensión tecnológica.

\section{III.3.1. La necesidad de convergencia}

El proceso de integración europea exige cambios en las AANN, tanto desde el punto de vista orgánico como funcional, que permitan afrontar los retos de gestión a que dan lugar las nuevas realidades.

Desde una posición orgánica es difícil llegar a conclusiones generalizables, habida cuenta de que los efectos que la gestión del Derecho comunitario ha impreso en los aparatos administrativos nacionales se ha realizado respetando el principio de autonomía institucional, más allá de que en todos los EEMM existe, aunque con diversas ubicaciones institucionales, un núcleo nacional de coordinación de los asuntos europeos.

Sin embargo, desde una perspectiva funcional, sí es fácilmente constatable que se están produciendo alteraciones profundas no sólo en las funciones que realizan las AANN, sino también en la forma de ejercerlas. Sirva a modo de ejemplo cómo la supresión de fronteras entre los EEMM obliga a redefinir las modalidades de control de los movimientos de personas y de la inspección de los flujos de mercancías, que deberán realizarse en origen o destino, pero ya no en la Administración fronteriza intracomunitaria (al menos en situaciones normales). $\mathrm{Y}$, por supuesto, la reducción del número de controles obliga a que los que se realicen sean más fiables. Por otra parte, es de esperar que las AANN respondan al influjo comunitario incrementando su capacidad de previsión y planificación, respetando las normas y obligaciones, dando mayor importancia a los mecanismos de coordinación, así como a los propios de seguimiento y control.

\section{III.3.2. Factores que favorecen la convergencia}

Entre las dimensiones que coadyuvan a conseguir una mayor convergencia (ya sea de manera directa o indirecta) entre las AANN, podemos citar los siguientes:

a) La aplicación de normas idénticas.

b) La introducción de nuevas pautas, procesos y métodos no conocidos en algunos EEMM. 
c) La creación de mercados unificados que, como ha sido puesto de manifiesto, modifica la actitud de los actores.

d) Los «poderes implícitos» como precondiciones para que alguna norma surta sus efectos, que favorecen la creación de coincidencias en cascada.

e) La jurisprudencia que homogeniza interpretaciones y la aplicación de los actos comunitarios. ${ }^{20}$.

f) La necesidad de estructuras de gobierno que funcionen con vocación de continuidad, que sean multifuncionales (para adaptarse al carácter horizontal y especializado de la integración europea), y que permitan la convivencia de identidades colectivas múltiples, ya sea conforme a criterios territoriales o funcionales.

g) Las primeras apariencias conducirían a afirmar que la situación institucional de los EEMM es demasiado divergente como para encontrar desarrollos comunes, pero aunque la heterogeneidad estructural e institucional sea grande, no es indominable. De acuerdo con Scharpf (2000: 194-195), en referencia a la política social pero el ejemplo es trasladable a otros ámbitos materiales, los Estados sociales europeos se pueden agrupar en «familias institucionales» que comparten raíces históricas específicas, orientaciones valorativas básicas, conceptos de soluciones y prácticas administrativas, y evoluciones comunes que les han obligado a afrontar situaciones similares. De esta manera, y salvando algunas situaciones mixtas, podríamos diferenciar: los Estados sociales escandinavos, los Estados continentales con transferencias sociales, los sistemas meridionales, y el modelo británico-irlandés.

h) La constatación de que todos los EEMM son Estados de Derecho y Estados democráticos. Que los países miembros sean Estados de Derecho implica para sus Administraciones que deben someterse al respeto del Derecho, a las reglas jurídicas, con independencia de cuáles sean las fuentes de las mismas, así como al control que sobre su cumplimiento puedan realizar los jueces. La relativa situación de preeminencia con que juega la Administración en algunos de los EEMM respecto a los ciudadanos y organizaciones privadas no significa que puedan eludir, al menos formalmente, el cumplimiento de la norma y sustraerse, en su caso, al correspondiente control jurisdiccional. Y que dichos países sean Estados democráticos significa para las Administraciones que no solamente deben estar subordinadas al Derecho, sino que también deben hacerlo respecto al poder político, emanación y representación práctica de la voluntad nacional. Es impensable que las AANN actúen de manera autónoma, regidas por un autopoder que conduciría a una suerte de dictadura administrativa; muy al contrario, todas ellas están bajo la dependencia de poderes surgidos de procesos democráticos en que los ciudadanos tienen la posibilidad de definirse ${ }^{21}$.

\section{III.3.3. Factores que frenan la convergencia}

Entre los aspectos que dificultan la obtención de una visión común, basada en las simetrías de los respectivos aparatos públicos de las AANN, podemos anotar los siguientes ${ }^{22}$ :

a) La no existencia de una noción unitaria de Administración Pública para las instituciones comunitarias. La interpretación comunitaria se orienta a criterios funcionales, que pueden modificarse con el paso del tiempo y de acuerdo con los segmentos materiales que se consideren.

b) Los textos comunitarios hablan fundamentalmente de «Estados» (aunque también de «Entes» y «Autoridades») de una manera indiscriminada, como si dicho término pudiera ser intercambiable por el de AANN; abundando un poco más, puede decirse que el término «Administración» se reserva para hacer referencia a las Administraciones subnacionales o a la propia organización administrativa comunitaria.

c) El carácter polisémico de la noción «servicio público», que una veces designa al organismo productor del servicio, mientras que otras se refiere a la misión de interés de general que se confía al organismo. Esa confusión puede incrementarse en la medida en que a veces tiende a utilizarse impropiamente la palabra «servicio público» como equiparable a «sector público», siendo además la apreciación de este último variable de acuerdo con las tradiciones y culturas administrativas de los distintos países.

d) La no existencia de una definición parangonable de «Administración Pública» en los distintos EEMM, diferenciándose tanto en la extensión orgánica de lo público como en los regímenes jurídicos y procedimentales de funcionamiento. Lo que, por otra parte, es coherente con el principio de autonomía institucional.

\section{III.3.4. Algunas acciones a emprender bacia la convergencia}

La convergencia administrativa no es sólo un imperativo de los tiempos, al que coadyuvan no pocas circunstancias del entorno contingente en que se mueven nuestras Administraciones, sino que puede ser objeto de un conjunto de acciones planificadas y bien definidas, como las que a continuación se detallan.

a) Reforzar la puesta en común de medios y recursos. Si las AANN vienen convergiendo a efectos funcionales, y si además los nuevos requerimientos de la integración europea modifican no sólo sus áreas de intervención pública, sino también la propia manera de intervenir, podemos afirmar que es pertinente un reforzamiento de la puesta en común de medios y recursos. Esto implica, claro está, una coordinación de la acción conjunta de las respectivas AANN, ya que, por ejemplo, no puede concebirse la realización por parte de los 
EEMM de las funciones aduaneras, en un territorio basado en la libre circulación, de manera unilateral y desconectada de los servicios administrativos afectados en el resto de Estados.

b) Fomentar el carácter impulsor de fórmulas y valores de gestión por parte de la UE. Habida cuenta de la capacidad difusora de las CCEE de determinadas maneras y valores de gestión de los asuntos comunitarios a nivel intraestatal, bien podría reconocerse su función catalizadora en la medida en que han favorecido la creación o desarrollo de algunas figuras administrativas (territoriales y no territoriales) de gran importancia. Mención especial merece la creación, consolidación o desarrollo de figuras que alientan la descentralización. En efecto, recuerda SPANOU (1999: 44-45), cómo la política regional europea y los fondos estructurales presentan «un aspecto de creación de instituciones que induce a ir hacia una convergencia limitada», así como que la creación y consolidación de las regiones en Grecia subraya hasta qué punto «la necesidad de una mayor eficacia de la implementación y gestión de los proyectos subvencionados por la CEE ha actuado como forma de presión a favor de responsabilidades en sentido opuesto al centro». Este proceso se ha potenciado más si cabe desde la institucionalización del Comité de las Regiones y Entes Locales, y la asunción del principio de subsidiariedad, por el TUE. Sea como sea, lo cierto es que hoy una buena parte de los EEMM cuentan con un reparto territorial del poder, ya sea mediante fórmulas federales, autonómicas o regionales (con sus correspondientes variantes) cuya implantación no habría tenido el mismo desarrollo cuantitativo y cualitativo sin el concurso de las acciones de las CCEE.

c) Necesidad de invertir en tecnología. La acción administrativa conjunta e integrada exige fuertes inversiones en nuevos medios tecnológicos que faciliten la gestión conjunta y la interacción entre la Administración comunitaria y las de los EEMM. De esta manera, debe proseguirse y potenciarse más el camino emprendido en las líneas siguientes: homologación de los recursos técnicos, buscando la compatibilidad de los mismos y la realización de economías de escala, lo que sin duda requiere que se siga trabajando en el establecimiento de estándares, normas y certificaciones armonizados; configurar redes europeas de comunicación; establecer fuentes informáticas comunes (bancos y bases de datos); aumentar las inversiones en nuevas tecnologías de la información y comunicación; y, sobre todo, no olvidar la capacitación de las personas que han de servirse de los recursos anteriores. Entre las acciones de cooperación que se han financiado en los últimos años podemos destacar dos: Euromethod, cuyo objetivo es establecer una metodología común de planificación y desarrollo de los sistemas de información para las AANN; e Insis, que intenta aplicar las tecnologías de la información para dar solución a los problemas de comunicación entre las instituciones comunitarias y los gobiernos de los EEMM. Tampoco debe olvidarse que esas nuevas tecnologías tienen que servir para mejorar el servicio a los ciudadanos, de ahí que una de las iniciativas de la Comisión se titule «eEurope. Una sociedad de la información para todos» y fije objetivos de dominio de la tecnología de la información e internet para los EEMM y la Comisión con el fin de ofrecer un mejor servicio. En este sentido, en 1995 la Comisión creó el sitio web «Europa», que actualiza continuamente y que hace funciones de nuevo sistema de información y comunicación con los ciudadanos (en noviembre de 1999 registró más de 100 millones de accesos). La Comisión cuenta además con un sistema de Intranet llamado «Europa Plus».

\section{Conclusiones}

I. El sistema político de la UE presenta un elenco de particularidades que condiciona la gestión pública intergubernamental que se produce en su seno. Algunas de ellas tienen que ver con la novedad que supone tal organización desde el punto de vista institucional y del procedimiento decisorio. Otras aluden al hecho de que sus funciones privilegian el diseño de regulaciones (ya sean éstas supranacionales o intergubernamentales) de carácter estratégico para las políticas públicas europeizadas (y aun en cada una de ellas con diferente incidencia), el control/evaluación de la aplicación de las mismas mediante diferentes instrumentos y actores, y la transferencia de recursos a las AANN. De manera que puede afirmarse que las organizaciones comunitarias no destinan tanto sus esfuerzos a cuestiones operativas ya que la implantación de las políticas es efectuada excepcionalmente por órganos comunitarios, siendo lo habitual que se realice a través de las AANN. Esto explica que cuando analicemos la gestión pública de la UE debamos aproximarnos a factores vinculados a la metodología analítica de la gestión intergubernamental.

II. Algunos de los factores o dimensiones de la gestión intergubernamental en la Unión Europea son los siguientes:

a) La regulación. El mayor rendimiento de la regulación intergubernamental comunitaria no deja de estar en cuestión: para algunos, la necesidad de negociar y concertar intereses complejos con actores diversos impulsan hacia un tipo de decisión subóptimo; para otros, sin embargo, los procesos de decisión comunitarios, basados en el consenso y en la integración de intereses, conducen a la adopción de decisiones de mejor calidad que la que adoptarían los EEMM individualmente y, sobre todo, sirven para responder mejor a la globalización que presenciamos. 
b) Las subvenciones intergubernamentales. Su importancia cuantitativa y cualitativa es innegable en el escenario comunitario. Por una parte, no sólo aportan recursos sino que también modifican la propia naturaleza de la acción pública alentando comportamientos de planificación, control y gestión indirecta y cooperativa, y ello sin menosprecio para el interés comunitario (no en vano se utilizan las subvenciones condicionadas frente a las genéricas).

c) El binomio centralización/descentralización tiene un significado muy preciso en el contexto comunitario. Ni la centralización se maximaliza, toda vez que existe una tendencia muy clara a permitir y propiciar la participación de las AANN (pero otorgando creciente importancia a las subnacionales) en todas las fases del laberinto decisional comunitario; ni la descentralización supone una transmisión de funciones, esencialmente de ejecución, sin cortapisas para las AANN, ya que la Administración comunitaria conserva potestades de control y, en su caso, de sanción. d) Por otro lado, resulta de interés constatar cómo el juego derivado del binomio centralización decisoria y de control versus descentralización ejecutiva vaya paulatinamente dando lugar a una cierta convergencia administrativa de los EEMM, fundada no tanto en la simetría que podría existir entre sus aparatos administrativos desde un punto de vista orgánico, como en aspectos funcionales. Con todo, tampoco deben magnificarse las diferencias, puesto que las AANN responden, en su configuración, estructuración y funcionamiento, a un número reducido de familias institucionales, y, además, existen acciones que deliberadamente nos orientan hacia aspectos comunes, como, por ejemplo, el incremento de la puesta en común de medios y recursos, el carácter creador e impulsor de instituciones que tiene el Derecho comunitario (piénsese en la importancia de los fondos estructurales para determinadas regiones), y las inversiones en medios tecnológicos que facilitan la interacción.
* Profesor de Ciencia Política y de la Administración. Facultad de Ciencias Politicas de la Universidad Complutense de Madrid.

${ }^{1}$ Entendemos por gestión «intergubernamental» no un concepto vinculado al procedimiento decisorio comunitario como opuesto a supranacional (y en este sentido se diferenciaría de la necesidad de un tipo de mayoría determinado, o de la obtención de unanimidad, para llegar a acuerdos en el ámbito del Consejo), sino una aplicación de la corriente metodológica de las Relaciones Intergubernamentales, que alude a las relaciones y transacciones cotidianas entre los componentes de distintas unidades de sistemas de gobierno territorialmente complejos.

${ }^{2}$ En este sentido H. Buller y K. HogGart (1998: 154-5) indican, refiriéndose a las políticas de medio ambiente de la Unión Europea, que los valores socioculturales se reemplazan por una formulación normativo-jurídica, mientras que los estándares de calidad que se establecen no parten de códigos de buenas conductas, sino de parámetros idealizados.

${ }^{3}$ Aun asumiendo las rigideces que se desprenden de cualquier taxonomía y las naturales dosis de cambio asociadas a la dinamicidad de la construcción europea (como por ejemplo los que derivarán de la ratificación y entrada en vigor del Tratado de Niza), consideramos su esquema suficientemente ilustrativo.

${ }^{4}$ F. W. SCHARPF (2000: 202)

3 Véase F. Morata (1998: 104).

- Nótese, por lo tanto, que son dichas directivas los actos comunitarios que mejor se acomodan al principio de subsidiariedad.

${ }^{7}$ Como estima F. W. SCharpf (2000: 38), esto pudiera explicar que la política comunitaria sea en mayor medida que la nacional resultado de la jurisprudencia. De ahí que sea curioso, y un tanto lamentable, que los politólogos europeos, preocupados en demasía por cuestiones institucionales y por el proceso decisorio comunitario, hayan menospreciado, afortunadamente con alguna excepción, los análisis del impacto de la construcción jurisprudencial sobre los ordenamientos jurídicos nacionales.

${ }^{8}$ Las herramientas que materializan las subvenciones intergubernamentales son esencialmente los fondos, considerados los instrumentos para la cohesión económica y social de la Unión. En la actualidad existen cuatro tipos: el Fondo Europeo de Orientación y Garantia Agraria (FEOGA), el Fondo Social Europeo (FSE), el Fondo Europeo de Desarrollo Regional (FEDER) y el Fondo de Cohesión.
9 Véase al respecto el Reglamento del Consejo núm. 1260/1999, de 21 de junio, especialmente el artículo 13.

${ }^{10}$ Artículos 9 y 34 del Reglamento citado.

"Considérese que la Comisión puede en todo momento requerir información o sugerir observaciones al Estado afectado.

${ }^{12}$ El término «gobernanza» viene a finalizar con una etapa de utilización de vocablos un tanto forzados y acaso algo alejados de la natural elegancia de nuestro idioma que, por otro lado, incurrían en no pocas ambiguiedades e inexactitudes. A nuestro juicio, "governance» o "gobernanza» abriga un contenido distinto al de los términos «gobierno», «gobernación» y «gobernabilidad», aunque en algunos rasgos pueda ser parcialmente coincidente.

${ }^{13}$ Así lo estima A. FernáNDEZ Tomás (1996: 174-177).

${ }^{14}$ Con todo, en la Cumbre de Niza (diciembre de 2000) se ha planteado la posibilidad de que en el año 2004 se produzca una Conferencia, de alcance comunitario europeo, para intentar delimitar competencias entre los diferentes niveles de gobierno en la Unión Europea. Dicha Conferencia, propiciada a instancia de los Länder y de nuestras Comunidades Autónomas, vendría a poner en entredicho el principio de autonomía institucional.

15 El Derecho comunitario debe cumplirse tanto si la ejecución es netamente administrativa, como en el caso en que con carácter previo se exija una ejecución normativa, estando ésta o no transferida a los poderes nacionales o subnacionales correspondientes.

${ }^{16}$ Téngase en cuenta que la institución encargada, con carácter general, de la preparación de las propuestas normativas en el pilar comunitario, la Comisión, no cuenta con los efectivos necesarios para obtener las informaciones pertinentes sobre los sectores objeto de regulación (teniendo además un buen porcentaje de sus servidores destinados a tareas de traducción). Como para comenzar un proceso de elaboración normativa se requiere establecer un diagnóstico sobre la situación de los sectores afectados, la propia institución no sólo ve con buenos ojos los contactos y la documentación que le puedan proporcionar los diferentes actores implicados, así como los lobbies correspondientes, sino que hasta ciento punto los propicia e incentiva.

${ }^{17}$ No pueden considerarse tal las oficinas informativas que la Comisión mantiene abiertas en los EEMM. 
${ }^{18} \mathrm{La}$ ejecución directa por parte del aparato administrativo comunitario es muy restringida, aunque en términos cualitativos pueda ser muy importante (por ejemplo, la aplicación de la política de la competencia).

19 Conviene recordar aquí también la actividad de los órganos jurisdiccionales nacionales, que actúan como colaboradores del TJCE en lo referido a la aplicación del Derecho comunitario.
20 Ésta y las anteriores dimensiones son citadas por Sparou (1999): 43).

${ }^{21}$ Véase la síntesis realizada por Jean Rrvero en Ch. Debbasch (dir.) (1988: 299.300).

2 De acuerdo con J. CRespo González (2001a).

\section{Bibliografía}

AAVV (1990), Las implicaciones administrativas de la integración económica regional: el ejemplo de la Comunidad Económica Europea. Enfoque comparado, Madrid: Ministerio para las Administraciones Públicas-Instituto Intemacional de Ciencias Administrativas.

Almuna Amann, J. (1990), «Discurso del Excmo. Sr. Ministro para las Administraciones Públicas. Acto inaugural», en AAVV, op. cit.: 10 y ss.

AL GORE (1993), Crear una Administración Pública que funcione mejor y cueste menos, Informe del National Perfomance Review, Vitoria: Instituto Vasco de Administración Pública.

Baena del Alcázar, M. (2000), Curso de Ciencia de la Administración, 4. ${ }^{a}$ edición reformada, Madrid: Tecnos.

Bañon R; RAmos, J. A., y Tamayo, M. (1995), «Sistema de Relaciones Intergubernamentales y legitimidad de la acción pública en el Estado de las Autonomías», Papeles de Trabajo (Gobiemo y Administración Pública) de la Fundación Ortega y Gasset, núm. AP, 20-XII-95.

Bañón, R., y Carrnlo, E. (coord.) (1997), La nueva Administración Pública, Madrid: Alianza Universidad Textos.

BULler, H., y HoGGART, K. (1998), «Pluralidad e implementación de políticas de medioambiente en la Unión Europea», Revista Internacional de Sociología, núms. 19 y 20, enero-agosto: 153-179.

Canales Aliende, J. M. (2001), «Gobernabilidad y gestión pública», en B. Olias DE Lima-GeTE (coord.) (2001), La Nueva Gestión Pública, Madrid, PrenticeHall: $35-48$.

Cassese, S., y Della Cananea, G. (1990) «Procedimiento de decisión: elaboración y aplicación de medidas de integración. Aspecto relativo a los Estados miembros», en AAVV, op. cit.: 69 y ss.

CASSESE, S. (1985), «Theoretical sketch of the cooperative and multidimensional nature of community bureaucracy», en J. JAMAR y W. WESSELS (eds.), Community bureaucracy at the crossroads, L'Administration communautaire à l'beure du cboix, Bruges: Colege of Europe.

ClaisSE, A. (1990), «Los agentes del proceso de integración. Aspecto relativo a los Estados miembros», en AAVV, op. cit.: 92 y ss.

Comisión Europea (2000), Libro Blanco de Reforma de la Comisión, I y II parte, COM (2000) 200 final, Bruselas, 5 de abril.

Crespo GonzÁlez, J. (2001a), «El concepto de Administración Nacional para la Unión Europea», Revista Universitaria Europea, núm. 2, en prensa.

- (2001b), «Gestión Pública y Gestión Intergubernamental en la Unión Europea», en B. Olias DE LLMa-GeTE (coord.), La nueva gestión pública, Madrid, Prentice-Hall: 337-367.

FERnÁNDEZ Tomás, A. (1996), «Las relaciones entre el Derecho comunitario y los Derechos nacionales», en R. HUESA VINALX (coord.), Instituciones de Derecho comunitario, Valencia, Tirant lo Blanch.

Gamero Casado, E. (1993), «La estructura orgánica de las Comunidades Autónomas en relación con la ejecución del Derecho Comunitario Europeo», en J. Barnes (ed.), La Comunidad Europea, la instancia regional y la organización administrativa de los Estados Miembros, Madrid: Civitas-Consejería de Presidencia de la Junta de Andalucía.

GL IBȦNEZ, A. (1998), El control y la ejecución del Derecho comunitario. El papel de las Administraciones nacionales y europea, Madrid: Instituto Nacional de Administración Pública.
Goma, R, y SubrRats, J. (1998) (coords.), Politicas puiblicas en España. Contenidos, redes de actores y niveles de gobiemo, Barcelona: Ariel.

KASSIM, H. (1994), «Policy networks and European Union policy making: a scep tical view», en West European Politics, 17/4.

Martin ACEBES, A. (1990), «Los agentes del proceso de integración. Caso del país anfitrión», en AAV, op. cit: 100 y ss.

METCALFE, L. (1993), «Gerencia de los procesos de integración: liderazgo, gestión y coordinación», Integración Latinoamericana, núm. 189-190, mayo-junio

- (1995), «La Comisión Europea como una organización-red», Gestión y Análisis de Politicas Públicas, núm. 4, septiembre-diciembre: 25-36.

- (1996), «Building capacities for integration: the future role of the Commission», Eipascope núm. 1996/2: 2 a 8.

Morata, F. (1995), «Unión Europea, Administraciones públicas y mercado interno», Gestión y Análisis de Políticas Públicas, núm. 4, septiembre-diciembre: 37.46.

- (1998), La Unión Europea. Procesos, actores y politicas, Barcelona: Ariel.

Muñoz MaChado, S. (1990), «La Comunidad Europea y el Derecho. Aspecto relativo a los Estados miembros», en AAVV, op. cit.: 42 y ss.

OCDE (1995), La gestion publique en mutation. Les reformes dans les pays de l'OCDE, Paris: OCDE.

- (1997), La transformación de la gestión pública. La reforma en los paises de la $O C D E$, Madrid: Boletin Oficial del Estado, Estudio preliminar a cargo de J. M. Canales Aliende y de J. M. Rodriguez Álvarez.

SCHARPF, F. W. (2000), Gobernar en Europa ieficaz y democráticamente?, Madrid: Alianza Editorial, traducido por Jesús Alborés Rey.

SIEDENTOPF, H., «Informe final», en AAVV (1990), op. cit.: 129 y ss.

Siedentopf, H., y HaUSCHIID, C. (1988a), «L'application des directives com munautaires par les Administrations nationales (étude comparative)», Revue Française d'Administration Publique, núm. 48, octubre-diciembre: 547-555.

Siedentopf, H., y Ziller, J. (1988b) (eds.), L'Europe des Administrations? La mise en oeuvre de la législation communautaire dans les États membres, vol. I, Syntbèses comparatives, Bruxelles: Institut Européen d'Administration Públique.

- (1988c) (eds.), L'Europe des Administrations? La mise en oeuvre de la législation communautaire dans les États membres, vol. II, Rapports nationaux, Bruxelles: Institut Européen d'Administration Públique.

Sobrino Heredia, J. M. (1997), «Principio de subsidiariedad y participación de los entes locales y regionales en la Unión Europea», en Noticias de la Unión Europea, núm. 145.

SPANOU, C. (1999), «La integración europea en términos administrativos: un marco para el análisis y el caso griego», Gestión y Análisis de Politicas Públicas, núm. 15, mayo-agosto: $30-50$.

UNGERER, W. (1990), «Procedimiento de decisión: elaboración y aplicación de medidas de integración. Aspecto comunitario", en AAVV, op. cit.: 58 y ss.

VAN GiNDERACHTER, J. (1990), «Los instrumentos de integración regional: los fondos estructurales de la Comunidad Económica Europea. Aspecto comunitario», en AAVV, op. cit: 109 y ss. 


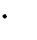

